\title{
Systemic thrombolysis with recombinant tissue plasminogen activator for acute life-threatening Blalock-Taussig shunt obstruction
}

\author{
Franco Diaz, William C. Sasser, Mark A. Law ${ }^{1}$, Jeffrey A. Alten ${ }^{1}$
}

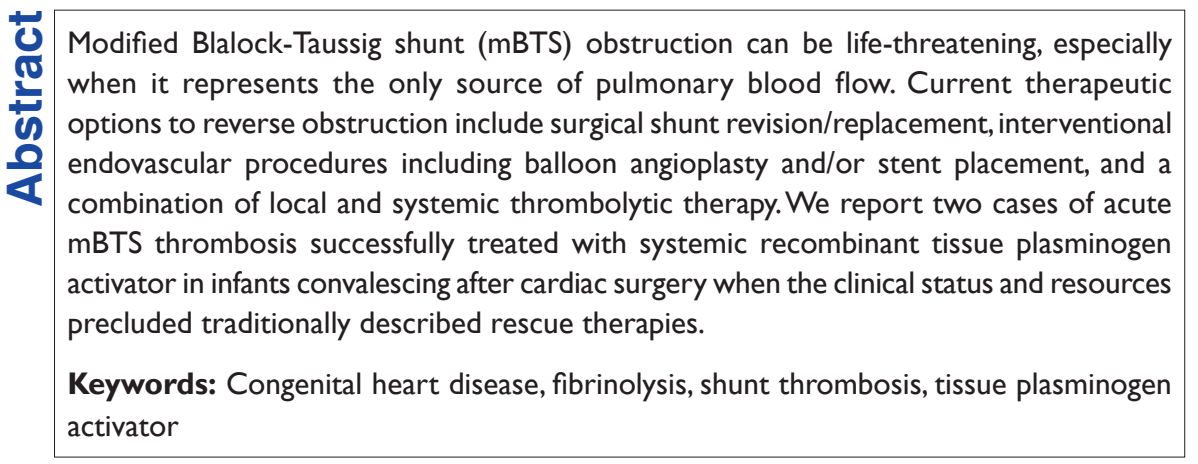

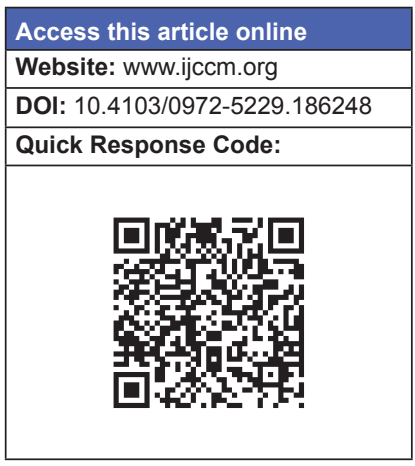

\section{Introduction}

Development of the Blalock-Taussig shunt in 1947 was a groundbreaking surgical intervention that prolonged the lives of many children with cyanotic congenital heart disease. The original procedure, which involved anastomosis of subclavian artery to pulmonary artery (PA), has been replaced by the modified Blalock-Taussig shunt (mBTS). The mBTS procedure involves placement of a polytetrafluoroethylene tube graft between the left subclavian artery and PA. The mBTS allows systemic to pulmonary blood flow and thus is most commonly utilized in children with anatomic obstruction to pulmonary blood flow such as pulmonary atresia. It is used as a temporizing measure in the neonatal period before more definitive cardiac palliation or repair is performed at a later age.

Obstruction from thrombosis is a life-threatening complication of mBTS. ${ }^{[1,2]}$ Treatment options include surgical revision/replacement, endovascular procedures

From:

Division of Pediatric Critical Care Medicine, 'Division of Pediatric Cardiology,

Section of Cardiac Critical Care Medicine, University of Alabama at Birmingham,

Birmingham, Alabama, USA

\section{Correspondence:}

Dr. Jeffrey A. Alten, University of Alabama, $17006^{\text {th }}$ Avenue South,

Suite 9100, Birmingham, Alabama 35233, USA.

E-mail: jalten@peds.uab.edu (balloon angioplasty and/or stent placement), and combination of local and systemic thrombolytics. ${ }^{[1,2]}$ Systemic thrombolytic therapy alone may be considered when other options are not promptly available. We report a successful treatment of acute mBTS obstruction using systemic recombinant tissue plasminogen activator (r-tPA) in two infants.

\section{Case Reports}

\section{Case 1}

Female weighing three kilograms with pulmonary atresia and intact ventricular septum underwent placement of $3.5 \mathrm{~mm}$ right mBTS (Gortex; WL Gore; Newark, DE) on the $3^{\text {rd }}$ day of life. Daily aspirin was started once full feeds were achieved. On postoperative day 10, aspiration episode was followed by profound hypoxemia and bradycardia. The patient was intubated, cardiopulmonary

This is an open access article distributed under the terms of the Creative Commons Attribution-NonCommercial-ShareAlike 3.0 License, which allows others to remix, tweak, and build upon the work non-commercially, as long as the author is credited and the new creations are licensed under the identical terms.

For reprints contact: reprints@medknow.com

How to cite this article: Diaz F, Sasser WC, Law MA, Alten JA. Systemic thrombolysis with recombinant tissue plasminogen activator for acute life-threatening BlalockTaussig shunt obstruction. Indian J Crit Care Med 2016;20:425-7. 
resuscitation (CPR) was initiated and she was given 100 units/kg intravenous (IV) heparin. Shunt murmur was not audible and there was no detectable end tidal $\mathrm{CO}_{2}$ despite heart ejection. Echocardiogram revealed no mBTS flow. Because extracorporeal membrane oxygenation (ECMO) support was not immediately available, two IV doses of $\mathrm{r}-\mathrm{tPA}(0.1 \mathrm{mg} / \mathrm{kg}$ at $30 \mathrm{~min}$ and $0.2 \mathrm{mg} / \mathrm{kg}$ at $40 \mathrm{~min})$ were given. Five minutes after the second dose, saturations suddenly rose to $70 \%$ with a return of spontaneous circulation. Veno-arterial ECMO was instituted $30 \mathrm{~min}$ later due to persistent hemodynamic instability despite appropriate oxygenation. She was weaned off ECMO $34 \mathrm{~h}$ later. Repeat echocardiogram and computed tomography angiogram revealed patent $\mathrm{mBTS}$. She survived to hospital discharge.

\section{Case 2}

Male weighing six kilograms with right dominant unbalanced atrioventricular canal defect, d-transposition of the great arteries, and severe PA stenosis underwent mBTS at 8 days of life. At 3 months of age, he underwent mBTS stenting in catheterization laboratory secondary to mBTS obstruction and resultant hypoxia. Three days following catheterization, he developed acute hypoxia and loss of mBTS flow murmur. No mBTS blood flow was observed by echocardiogram. The child was given 100 units/kg IV bolus of heparin and escalated respiratory support with no improvement in hypoxemia. Lactic acidosis and increased cardiovascular support ensued. Because catheterization and/or surgical support was not immediately available, decision was made to attempt systemic thrombolysis (IV bolus $0.2 \mathrm{mg} / \mathrm{kg}$ r-tPA followed by $0.5 \mathrm{mg} / \mathrm{kg} / \mathrm{h}$ infusion). Ninety minutes into infusion, the child had a sudden resolution of hypoxia and return of shunt murmur. mBTS flow was confirmed with an echocardiogram. Significant hemorrhage from previous catheterization site occurred during infusion resolving to local pressure. He subsequently underwent PA reconstruction and right ventricle to PA conduit. mBTS was patent when taken down during surgery.

\section{Discussion}

Occlusion of systemic-to-pulmonary arterial shunts due to thrombus is not uncommon, with reported incidence ranging from $3 \%$ to $20 \% .{ }^{[1]}$ Most common presentation of acute thrombosis is sudden, profound hypoxemia. ${ }^{[1]}$ Management depends on symptoms and available resources. In our series, shunt thrombosis in case one led to the absence of pulmonary blood flow with resultant cardiac arrest, while the presence of some minimal prograde pulmonary blood flow in case two resulted in refractory hypoxemia with severe hemodynamic compromise.
If resources and clinical condition permit, surgical shunt revision/replacement or interventional catheterization should be considered for mBTS thrombosis as they have demonstrated efficacy in the literature and may confer less risk of life-threatening bleeding relative to system r-tPA administration. The various catheter-based techniques (local thrombolytic therapy, stent placement, balloon angioplasty) are the preferred management for mBTS occlusion; they are highly successful and potentially avoid high-risk reoperation for shunt replacement or revision. ECMO utilization has been described for patient stabilization and to facilitate cardiac catheterization or reoperation. Efficacy of heparin administration for resolution of thrombosis (partial or complete) has not been studied or reported. A combination of local (through a catheter placed proximal to the clot) and systemic thrombolytic therapy has been reported for acute shunt thrombosis. ${ }^{[2]}$

There is no consensus on the optimal indication(s), efficacy, and safety of r-tPA. ${ }^{[3,4]}$ Pediatric dosing recommendations have been derived from adult data, with dosing ranging from "low" dose $(0.03 \mathrm{mg} / \mathrm{kg} / \mathrm{h})$ to "high" dose $(0.6 \mathrm{mg} / \mathrm{kg} / \mathrm{h}) \cdot{ }^{[3-5]}$ Uncertainty of dosing is reflected in our cases. While bolus dosing is not routinely described, we elected to give an initial loading dose given the urgency to restore pulmonary flow.

A relative contraindication to $\mathrm{r}$-tPA administration is use within 7-10 days of major surgery, a factor that must be considered in postoperative cardiac patients. ${ }^{[3]}$ The incidence of bleeding complications related to thrombolysis varies widely, $0-40 \% \cdot{ }^{[3,4]}$ Our second patient developed significant bleeding from a cardiac catheterization site 3 days old, highlighting this risk. As bleeding risks are theoretically lower when r-tPA is given locally, this is the preferred method of administration if feasible.

By re-establishing adequate PA blood flow, both of our patients avoided worse morbidity and potential mortality. Our first patient's sudden improvement in oxygenation led to the return of spontaneous circulation and cessation of CPR. Though she ultimately went on $\mathrm{ECMO}$, cannulation was completed without additional $30 \mathrm{~min}$ of CPR and profound hypoxemia. r-tPA administration in our second child led to a reversal of severe hypoxemia and acidosis, allowing him to undergo definitive treatment.

We propose the treatment algorithm in Figure 1 for acute, life-threatening mBTS thrombosis. We recognize quality data to support fibrinolytic therapies for this 


\section{ALGORITHM}

Clinical suspicion of life threatening mBTS obstruction

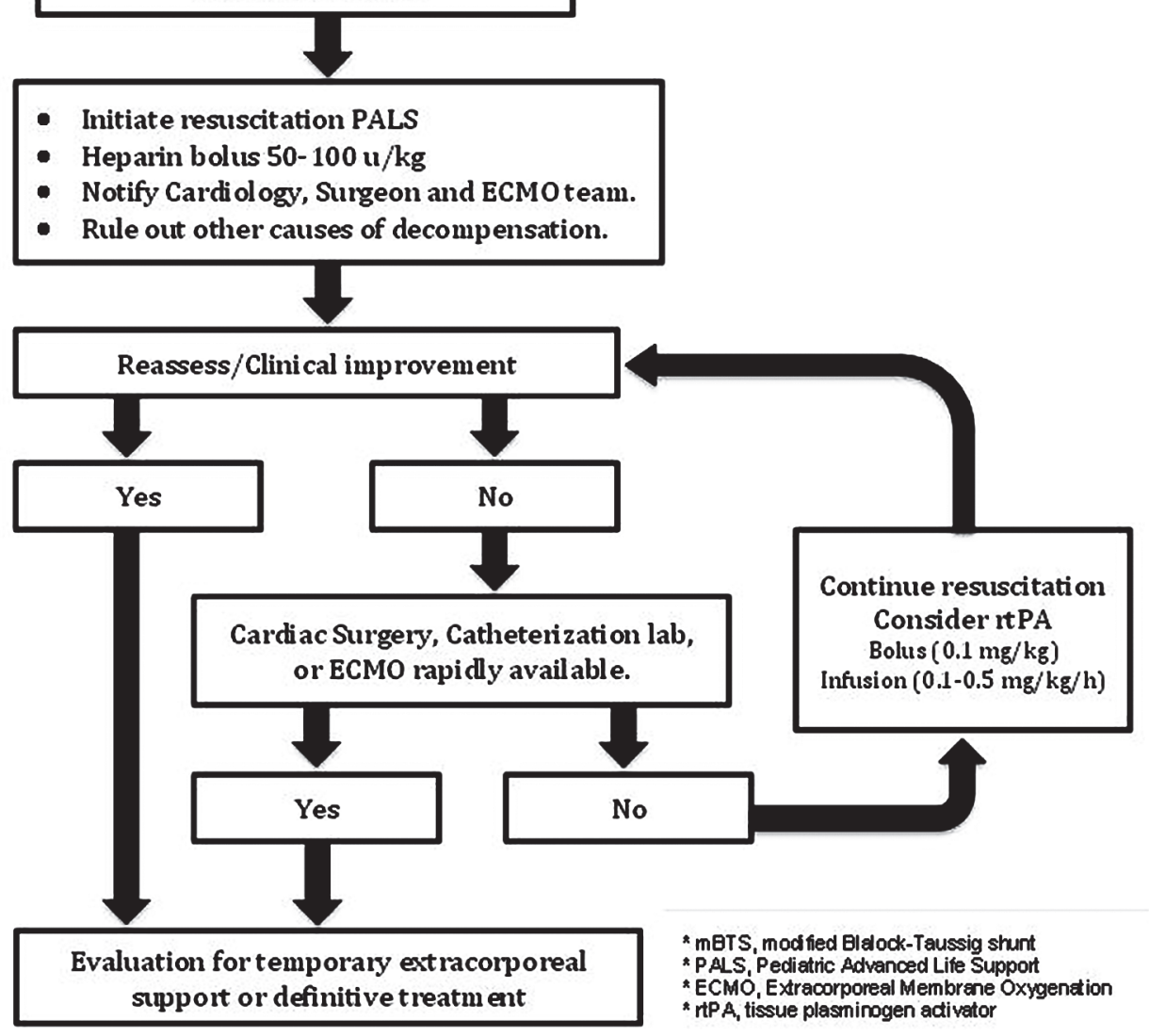

Figure I: Proposed algorithm for acute life-threatening modified Blalock-Taussig shunt obstruction management

situation is lacking. If cardiac catheterization, cardiac surgery, or ECMO are not available in a patient with acute mBTS occlusion, given the high likelihood of significant morbidity and/or mortality, we believe fibrinolytic therapy is warranted due to its superior efficacy when compared to anticoagulation alone. ${ }^{[2,3,5]}$

\section{Conclusion}

Systemic r-tPA administration can be considered as rescue therapy for life-threatening mBTS shunt thrombosis when rapid cardiac catheterization or surgery is not feasible. This may be particularly important when patients present critically ill to nontertiary centers. Future studies are needed to determine the efficacy and safety of systemic r-tPA for mBTS thrombolysis.

\section{Financial support and sponsorship}

This study was supported by the University of Alabama at Birmingham, Division of Pediatric Cardiology, Section of Cardiac Critical Care Medicine Departmental Funds.

\section{Conflicts of interest}

There are no conflicts of interest.

\section{References}

1. Moszura T, Zubrzycka M, Michalak KW, Rewers B, Dryzek P, Moll JJ, et al. Acute and late obstruction of a modified Blalock-Taussig shunt: A two-center experience in different catheter-based methods of treatment. Interact Cardiovasc Thorac Surg 2010;10:727-31.

2. Kogon B, Villari C, Shah N, Kirshbom P, Kanter K, Kim D, et al. Occlusion of the modified Blalock-Taussig shunt: Unique methods of treatment and review of catheter-based intervention. Congenit Heart Dis 2007;2:185-90.

3. Manco-Johnson MJ, Grabowski EF, Hellgreen M, Kemahli AS, Massicotte MP, Muntean W, et al. Recommendations for tPA thrombolysis in children. On behalf of the scientific subcommittee on perinatal and pediatric thrombosis of the scientific and standardization committee of the international society of thrombosis and haemostasis. Thromb Haemost 2002;88:157-8.

4. Monagle P, Chan A, Goldenberg NA, Ichord RN, Joyrneycake JM, et al. Antithrombotic therapy in neonates and children: American College of Chest Physicians Evidence-Based Clinical Practice Guidelines $\left(9^{\text {th }}\right.$ Edition). Chest 2012;133:887S-968S.

5. Santiago MJ, Lopez-Herce J, Del Castillo DB. Thrombolytic therapy using a low dose of tissue plasminogen activator in children. Catheter Cardiovasc Interv 2014;83:339-40. 